\title{
Continuing mortality and morbidity from smallpox vaccination
}

\author{
GILLIAN C L DU MONT, RICHARD C BEACH
}

British Medical fournal, 1979, 1, 1398-1399.

\section{Summary and conclusions}

Three cases of cross-infection after smallpox vaccination are described, in two of which the outcome was fatal. Probably all occurred because simple precautions were not observed at the time of vaccination-for example, exclusion of contraindications and warnings about risks.

If those countries still requiring evidence of vaccination for entry were to abolish this rule, however, the risk of cross-infection could be eliminated. Vaccinating a person with contraindications is justified only when exposure to smallpox has occurred.

\section{Introduction}

Although routine smallpox vaccination of infants was discontinued in the UK in 1971, there continues to be a fairly constant morbidity and mortality from the complications of vaccination. Since the beginning of 1975 some $20-28$ cases of complications of vaccination have been reported yearly to the Communicable Disease Surveillance Centre. ${ }^{1}$

We report three cases treated by us at this hospital since 1976, illustrating that serious complications of smallpox vaccination still occur. The diagnosis was confirmed in all cases by electron microscopy and isolation of vaccinia virus on cell culture.

\section{Case reports}

Case 1-A 3-year-old Bangladeshi boy who had suffered from moderately severe eczema since the age of 6 months presented with a three-day history of rapidly progressive rash, fever, and malaise. Seven days earlier the family had attended their general practitioner for smallpox vaccination because of a planned visit to Bangladesh. The parents were revaccinated and the two elder sibs, aged 7 and 8 , given primary vaccination. Although the patient was not vaccinated because of his eczema, the parents were not warned about the risk of cross-infection. As the patient often shared the bed of his older brother cross-infection was inevitable. Examination showed a toxic child with a temperature of $37^{\circ} \mathrm{C}$ and extensive areas of umbilicated vesicles on the face and arms. Eczema vaccinatum was diagnosed. Despite intensive treatment with human antivaccinial globulin (AVIG), methisazone, antibiotics, and intravenous feeding he died 15 days after admission with generalised vaccinia and extensive skin loss.

Case 2-An 18-month-old West Indian boy who had suffered from moderately severe eczema from the age of 3 months presented with a six-day history of rash, fever, and rigors. Examination showed a feverish, toxic, irritable infant with a large, bleeding excoriated area around the right ear (fig 1) and areas of umbilicated vesicles on the face, arms, legs, and genitalia. Eczema vaccinatum was confirmed. He was treated with AVIG, methisazone, and antibiotics, and after a stormy, protracted illness recovered. Inquiry disclosed that he had sat briefly on the lap of his 7-year-old cousin, who had received a primary vaccination in the thigh nine days earlier before a visit to Barbados. Barbados did not require a certificate of vaccination at the time.

St Thomas's Hospital, London SE1 7GH

GILLIAN C L DU MONT, MRCP, DCH, paediatric lecturer RICHARD C BEACH, MRCP, BSC, paediatric registrar

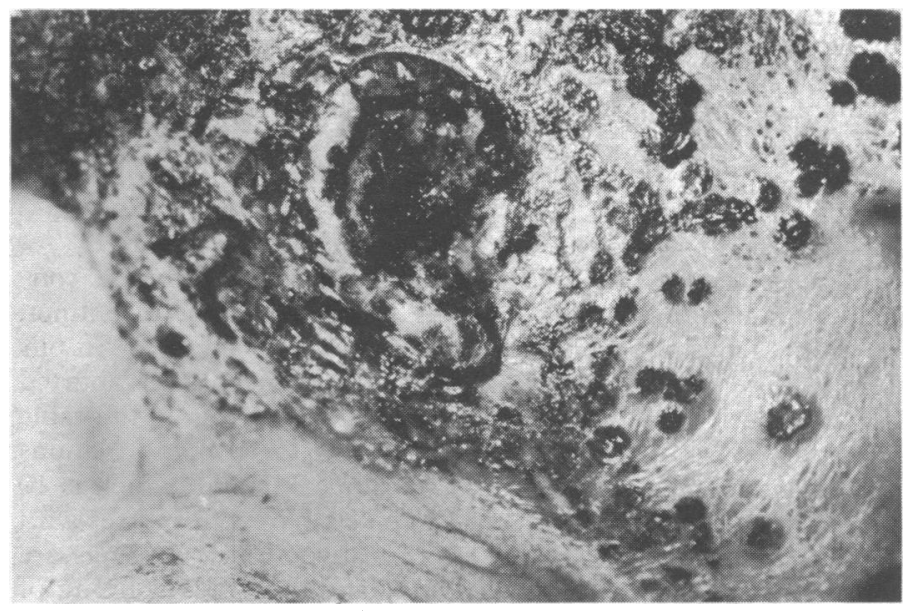

FIG 1-Appearances of eczema vaccinatum in case 2 .

Case 3-A 28-year-old Caucasian woman received primary vaccination at 20 weeks of gestation before visiting South Africa. She was not told of the possible risks to her unborn child and no precautions were taken. At 28 weeks she delivered a $1000-\mathrm{g}$ male infant with widespread vesicular skin lesions (fig 2). Despite AVIG the infant died on the fourth day. Vaccinial lesions were found in many organs at necropsy.

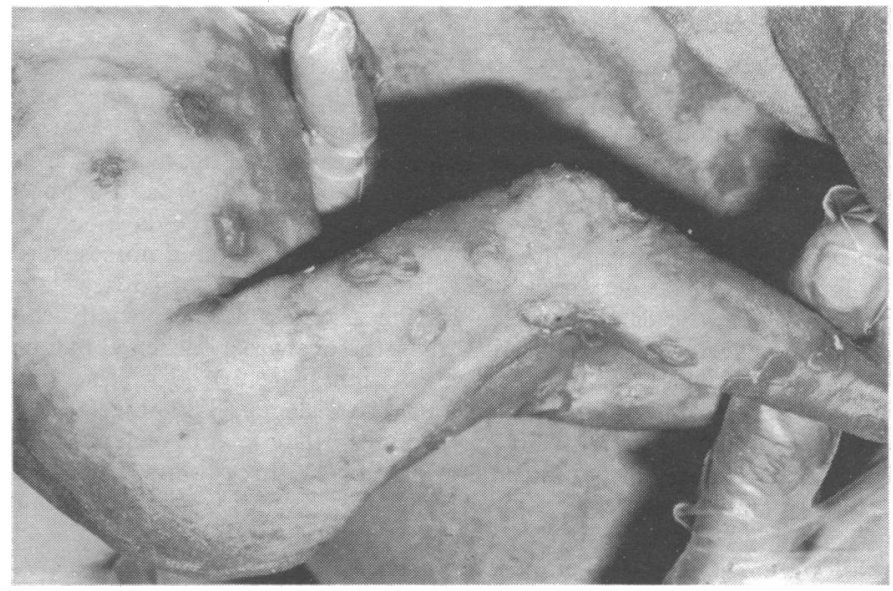

FIG 2-Vesicular lesions present at birth in case 3.

\section{Comment}

The last report of smallpox resulting from person-to-person transmission occurred in Somalia in October 1977. Nevertheless, a valid smallpox vaccination certificate is still required by some countries, although the number is declining. Before vaccination a careful history must be taken to exclude contraindications in the patient and household contacts-for example, immunosuppression, pregnancy, and skin disorders. Furthermore, any person with eczema should be separated for at least 21 days from a recently vaccinated member of the household. 
Vaccinating a person with contraindications is justified only when exposure to smallpox has occurred.

Most countries requiring vaccination on entry will waive the regulations if there are contraindications, but this should first be checked with the relevant authority. A doctor's letter, preferably signed and stamped by a vaccinating authority, should then be issued for presentation to the health authority on arrival stating that vaccination is contraindicated for medical reasons.

If despite contraindications a patient must be vaccinated it should be carried out under cover of AVIG. So far as we know transplacental transmission of vaccinia virus has not been reported when this precaution has been taken. Had the simple precautions outlined in the Memorandum on Vaccination against Smallpox ${ }^{2}$ been carried out the above cases might not have occurred. If those countries still requiring evidence of smallpox vaccination on entry were to abolish this requirement, however. the risks could be completely eliminated.

We thank Professor J Banatvala for helpful criticism and advice, and Professor J W Scopes and Dr B D R Wilson for permission to report these cases.

\section{References}

1 Communicable Disease Surveillance Centre, Report, No 20. London, CDSC, 1978.

2 Department of Health and Social Security, Memorandum on Vaccination against Smallpox. London, DHSS, 1974.

(Accepted 2 April 1979)

\section{SHORT REPORTS}

\section{Reversal of lactic acidosis associated with heart failure by nitroprusside administration}

Since Taradash $^{1}$ reported the favourable effect of nitroprusside in idiopathic lactic acidosis, no further confirmation of this therapeutic approach has been reported. We describe here another patient with severe lactic acidosis who responded dramatically to nitroprusside.

\section{Case report}

A 76-year-old woman was admitted to hospital because of recurrent abdominal pain 15 years after cholecystectomy. She was known to suffer from heart failure and diabetes mellitus. On admission the patient was in shock with profound peripheral vasoconstriction. Her temperature was $37^{\circ} \mathrm{C}$. Jugular vein distention, rales at lung bases, and upper abdominal tenderness were noted. Arterial blood disclosed a severe metabolic acidosis (see figure). Blood urea nitrogen was $15 \mathrm{mmol} / 1(42 \mathrm{mg} / 100 \mathrm{ml})$, glucose $8.9 \mathrm{mmol} / 1(160 \mathrm{mg} / 100 \mathrm{ml})$, serum amylase $1230 \mathrm{IU} / \mathrm{l}$, and bilirubin 48 $\mu \mathrm{mol} / 1(2.8 \mathrm{mg} / 100 \mathrm{ml})$. The anion gap was $39 \mathrm{mmol}(\mathrm{mEq}) / 1$ and attributed to lactate excess.

After $132 \mathrm{mmol}$ bicarbonate the blood $\mathrm{pH}$ rose to 7.28 and blood pressure to $120 / 80 \mathrm{~mm} \mathrm{Hg}$. Nevertheless, peripheral cyanosis diminished only very slightly and anuria persisted. Frusemide $80 \mathrm{mg}$ and nitroprusside $0.5-1 \mu \mathrm{g} /$ $\mathrm{kg} / \mathrm{min}$ were administered. Peripheral cyanosis gradually disappeared, the skin became warm, polyuria ensued, the blood $\mathrm{pH}$ rose abruptly to $7 \cdot 41$, and the anion gap decreased to $20 \mathrm{mmol} / \mathrm{l}$. The patient improved considerably and a few days later was discharged.

Three weeks later she was readmitted in a similar condition, again with considerable peripheral vasoconstriction and a large anion gap metabolic acidosis. Serum lactate concentration was $11.2 \mathrm{mmol} / 1(100 \mathrm{mg} / 100 \mathrm{ml})$. The administration of nitroprusside was again accompanied by a striking diminution of the peripheral cyanosis, an increase in urine output, and a progressive correction of the metabolic acidosis, without further administration of bicarbonate (see figure). Nevertheless, the serum lactate concentration took a further 24 hours to decrease to $2 \cdot 2 \mathrm{mmol} / 1(20 \mathrm{mg} / 100 \mathrm{ml})$.

Despite haemodynamic improvement the serum bilirubin concentration rose to $428 \mu \mathrm{mol} / 1(25 \mathrm{mg} / 100 \mathrm{ml})$. Percutaneous transhepatic cholangiography showed marked dilation of the biliary tree. Owing to the patient's poor general condition an operation was not performed and the patient died.

\section{Comment}

Recurrent lactic acidosis in this patient was due to advanced heart failure with decreased peripheral tissue perfusion decompensated by pancreatitis and obstructive jaundice. ${ }^{2}$ Further myocardial depression by acidosis precipitated circulatory collapse with extreme vasoconstriction, oligoanuria, and perpetuation of lactic acidosis.

By improving cardiac performance and tissue perfusion nitroprusside prevented intracellular anaerobic metabolism and allowed for a rapid reversal of lactate production. The ensuing complete correction of acidosis contrasted with the small changes in $\mathrm{pH}$ induced by the bicarbonate administered before nitroprusside, creating even a transient "overshoot alkalosis"3 during her first admission.

The concurrent correction of metabolic acidosis with the administration of nitroprusside is surprising in view of the potentially increased production of lactate by cyanide. ${ }^{4}$ Nevertheless, the repetition twice of a similar sequence of events and its resemblance to the events reported by Taradash ${ }^{1}$ weigh heavily in favour of a cause-and-effect relationship.

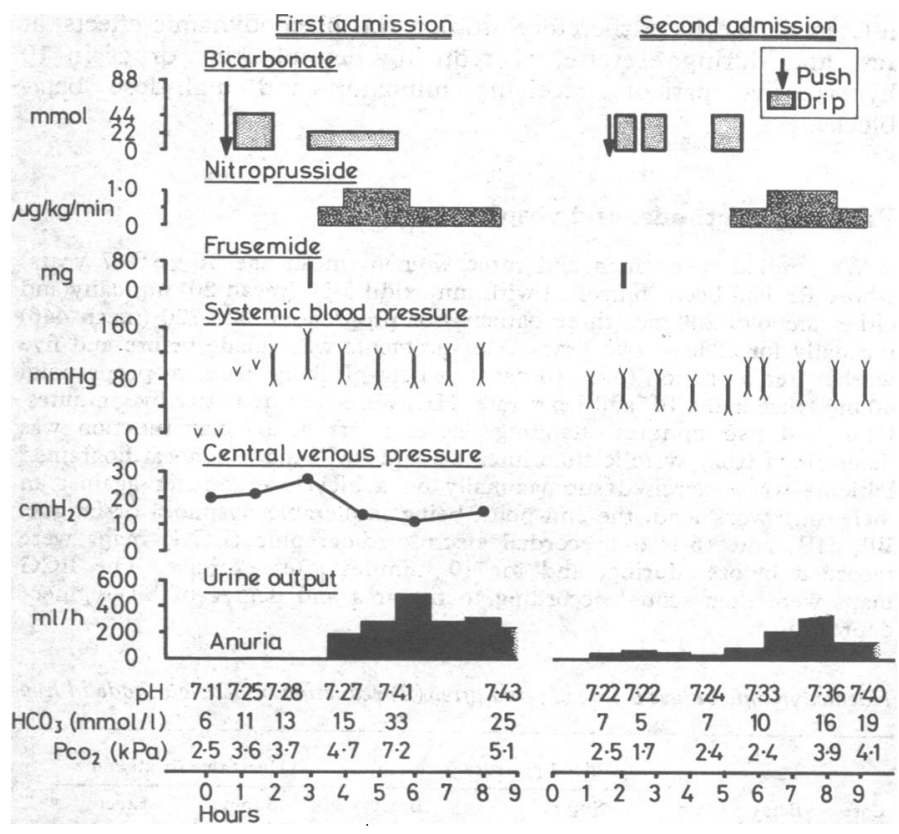

Serial arterial blood gases and haemodynamic parameters before, during, and after treatment on first and second admission.

Conversion: SI to traditional units- $\mathrm{HCO}_{3}: 1 \mathrm{mmol} / 1=1 \mathrm{mEq} / 1 . \mathrm{PcO}_{2}$ : $1 \mathrm{kPa} \approx 7.5 \mathrm{~mm} \mathrm{Hg}$.

Interestingly, during the first admission the anion gap returned towards normal as soon as acidosis was corrected whereas in the last admission the serum lactate remained raised for several hours after the correction of acidosis. This lag period' may have been due to the onset of hepatic insufficiency on the second admission. On that occasion the liver may have failed to remove lactate efficiently from the extracellular space, although improved tissue oxygen delivery had already reversed intracellular lactic acid production.

These data support the concept that nitroprusside may be an important therapeutic agent in combating "overproduction" lactic 